\title{
Degradation of trinitrophenol by sequential catalytic wet air oxidation and solar $\mathrm{TiO}_{2}$ photocatalysis
}

\author{
Athanasia Katsoni ${ }^{a}$, Helder T. Gomes ${ }^{\text {b,c }}$, Luisa M. Pastrana-Martínez ${ }^{c}$, Joaquim L. Faria ${ }^{c}$, \\ José L. Figueiredo ${ }^{\mathrm{c}}$, Dionissios Mantzavinos ${ }^{\mathrm{a}, * *}$, Adrián M.T. Silva ${ }^{\mathrm{c}, *}$ \\ a Department of Environmental Engineering, Technical University of Crete, Polytechneioupolis, GR-73100 Chania, Greece

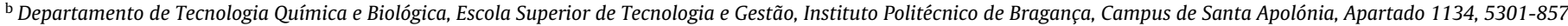 \\ Bragança, Portugal

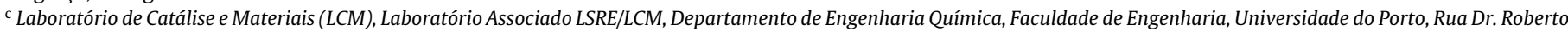 \\ Frias s/n, 4200-465 Porto, Portugal
}

\section{A R T I C L E I N F O}

\section{Article history:}

Received 29 March 2011

Received in revised form 9 June 2011

Accepted 10 June 2011

\section{Keywords:}

Water treatment

CWAO

Activated carbon

Process integration

Solar photocatalysis

\begin{abstract}
A B S T R A C T
Catalytic wet air oxidation (CWAO) and solar $\mathrm{TiO}_{2}$ photocatalysis were investigated as advanced oxidation processes to degrade trinitrophenol (TNP) in model aqueous solutions. An activated carbon (AC) treated with sulphuric acid of different concentrations $(5,10$ and $18 \mathrm{M}$ ) at two different temperatures (353 and $423 \mathrm{~K}$ ) was investigated as a metal-free CWAO catalyst, while a commercially available $\mathrm{P} 25 \mathrm{TiO}_{2}$ powder was used as a photocatalyst. CWAO experiments were conducted at $448 \mathrm{~K}, 0.7 \mathrm{MPa}$ oxygen pressure (4.7 MPa of total pressure), $1.3 \mathrm{~g} \mathrm{~L}^{-1}$ AC loading and $270 \mathrm{mg} \mathrm{L}^{-1} \mathrm{TNP}$ concentration, while photocatalytic experiments were conducted at ambient temperature, $1 \mathrm{~g} \mathrm{~L}^{-1}$ photocatalyst loading, $500-1000 \mathrm{~W} \mathrm{~m}^{-2}$ irradiance provided by a solar simulator and $32-270 \mathrm{mg} \mathrm{L}^{-1}$ TNP concentration. Treatment efficiency was assessed by measuring the concentrations of TNP and nitrates, total organic carbon (TOC) and biochemical oxygen demand $\left(\mathrm{BOD}_{5}\right)$. Up to $90 \%$ TNP degradation was attained during CWAO over $120 \mathrm{~min}$, from an initial concentration of $270 \mathrm{mg} \mathrm{L}^{-1}$. For the same TNP concentration, $\mathrm{TiO}_{2}$ photocatalysis gives only $13 \%$ conversion over the same $120 \mathrm{~min}$. However, for TNP concentrations below $144 \mathrm{mg} \mathrm{L}^{-1}$, photocatalysis can be effectively used: 100 and $80 \%$ TNP degradation obtained in 120 min of irradiation for initial TNP concentrations of 64 and $144 \mathrm{mg} \mathrm{L}^{-1}$, respectively. In this respect, CWAO and photocatalysis were employed sequentially to treat TNP; complete TNP conversion being achieved after $120 \mathrm{~min}$ of CWAO followed by $60 \mathrm{~min}$ of photocatalysis at $1000 \mathrm{~W} \mathrm{~m}^{-2}$ irradiance, and this was accompanied by $82 \%$ TOC reduction, as well as an increase of $\mathrm{BOD}_{5} / \mathrm{TOC}$ ratio from 0 to 2.28 .
\end{abstract}

(c) 2011 Elsevier B.V. All rights reserved.

\section{Introduction}

Advanced oxidation processes (AOPs) are remediation solutions based on the generation of non-selective and highly reactive radicals, such as hydroxyl $\left(\mathrm{HO}^{\circ}\right)$ and hydroperoxyl $\left(\mathrm{HOO}^{\circ}\right)$ radicals, applied to oxidise persistent organic pollutants into carbon dioxide and water, or alternatively into easily biodegradable byproducts. Briefly, heterogeneous photocatalysis is based on the irradiation of a semiconductor material with photons of energy equal to or greater than its band-gap energy, to produce reactive electron-hole $\left(\mathrm{e}^{-} / \mathrm{h}^{+}\right)$pairs and, subsequently, highly oxidising species $[1,2]$. Titanium dioxide $\left(\mathrm{TiO}_{2}\right)$ is the most commonly used

\footnotetext{
* Corresponding author. Tel.: +351 225081582; fax: +351 225081449.

** Corresponding author. Tel.: +30 2821037797; fax: +30 2821037852.

E-mail addresses: mantzavi@mred.tuc.gr (D. Mantzavinos), adrian@fe.up.pt (A.M.T. Silva).
}

photocatalyst due to its high efficiency to produce $\mathrm{e}^{-} / \mathrm{h}^{+}$pairs and also because it is a chemically stable, non-toxic and low cost material $[1,3,4]$.

Ambient conditions of temperature and pressure are typical in photocatalysis. In contrast, wet air oxidation (WAO) operates at harsh conditions, which can become milder in the presence of active catalysts (400-523 K, 0.5-5.0 MPa) [5-15]. Several heterogeneous catalysts based on supported or unsupported metal oxides (e.g., $\mathrm{Cu}, \mathrm{Zn}, \mathrm{Mn}, \mathrm{Fe}, \mathrm{Co}$, and $\mathrm{Bi}$ ) and noble metals (e.g., $\mathrm{Ru}, \mathrm{Pt}, \mathrm{Pd}$ and $\mathrm{Rh}$ ) have been tested in the last four decades for catalytic wet air oxidation (CWAO) [5-11,13,14]. However, deactivation phenomena are frequent, such as leaching of active metals to the liquid phase. For this reason, metal-free carbon materials have been tested as catalysts in many CWAO applications, including activated carbons [15-24], carbon xerogels [20,25], multi-walled carbon nanotubes [26-28] and carbon foams and fibres enriched with nitrogen [29]. Carbon materials are very versatile catalysts, since their surface chemistry can be easily 
modified [30] in order to provide adequate active sites for the reaction.

2,4,6-Trinitrophenol (TNP), also known as picric acid, is a byproduct of the industrial synthesis of nitrobenzene. The resulting waste is an aqueous stream at the processing temperature (above $348 \mathrm{~K}$ ) and a solid when left at ambient temperature. The raw effluent resulting from the nitrobenzene synthesis can be treated in situ by CWAO, taking advantage of the high temperature at which it is released and allowing for important energy savings. Indeed, recent works show that carbon materials with no added metal phase can be used as highly efficient catalysts for degradation of TNP by CWAO at $473 \mathrm{~K}[23,25]$. In comparison with other AOPs, CWAO is also the most appropriate technology to treat wastewaters with moderate or high organic content (chemical oxygen demand of 10-100 $\mathrm{g} \mathrm{L}^{-1}$ ) [12]. However, since large scale CWAO is capital cost intensive when compared to other AOPs, coupling small cost effective CWAO units with another AOP post-treatment could represent an economically favourable solution for many specific instances.

Amongst AOPs operating at less severe conditions than those used in CWAO, heterogeneous photocatalysis is earning stronger relevance since the degradation process can be driven by solar light. Additionally, it was recently reported that photocatalysis could be beneficial when applied as a secondary treatment to WAO [31].

In the present work, an activated carbon commonly used for wastewater treatment (Norit ROX 0.8), with modified surface chemistry, was studied as a metal-free CWAO catalyst. Then, $\mathrm{TiO}_{2}$ heterogeneous photocatalysis driven by artificial solar light was investigated as a possible post-treatment to totally degrade TNP.

\section{Experimental}

\subsection{Reagents and materials}

2,4,6-Trinitrophenol $\left(\mathrm{C}_{6} \mathrm{H}_{3} \mathrm{~N}_{3} \mathrm{O}_{7}, 98 \%\right)$, acetic acid (99.8\%), sodium dihydrogen phosphate $(\geq 99 \%)$ and phosphoric acid (85\%) were purchased from Sigma-Aldrich. Acetonitrile (99.8\%) and methanol (99.8\%) were of HPLC grade (Chromanorm). Ultrapure water was produced in a Direct-Q millipore system.

\subsection{CWAO experiments}

Different activated carbon samples were tested as CWAO catalysts, namely the as-received original activated carbon Norit ROX 0.8 (AC), and chemically modified carbon materials obtained from the same $A C$ by liquid phase treatments, following the procedure reported elsewhere [32]. Samples were treated with three different sulphuric acid concentrations $(5,10$ and $18 \mathrm{M})$ at two different temperatures (353 and $423 \mathrm{~K}$ ), and labelled as $A C X-Y$, where $X$ refers to the sulphuric acid concentration and $Y$ to the temperature (e.g., AC5-353 refers to a sample treated with $5 \mathrm{M}$ sulphuric acid at $353 \mathrm{~K}$ ). In a typical treatment, $10 \mathrm{~g}$ of AC were immersed in $200 \mathrm{~mL}$ of the sulphuric acid solution for $3 \mathrm{~h}$ in a $500 \mathrm{~mL}$ roundbottom flask heated by an oil bath at the desired temperature. Then, the recovered samples were thoroughly washed with distilled water until the neutrality of the rinsing waters was reached, and further dried in an oven for $18 \mathrm{~h}$ at $383 \mathrm{~K}$. The specific surface area $\left(S_{\mathrm{BET}}\right)$, the non-microporous surface area determined by the $t$-method ( $\left.S_{\mathrm{MES}}\right)$ and the micropore volume $\left(V_{\mathrm{MIC}}\right)$ were calculated from the $\mathrm{N}_{2}$ adsorption isotherms that were obtained in a Quantachrome NOVA 4200e analyser. The amounts of surface groups released as $\mathrm{SO}_{2}$ were determined as described elsewhere [32], by using temperature programmed desorption in a AMI-200 apparatus (Altamira Instruments), equipped with a quadrupole mass spectrometer (Dymaxion, Ametek). Thermogravimetric analysis (TGA) was also performed for selected samples by using a STA
$490 \mathrm{PC} / 4 / \mathrm{H}$ Luxx Netzsch thermal analyser and heating the samples at $20 \mathrm{~K} \mathrm{~min}^{-1}$ under nitrogen flow $\left(50 \mathrm{~cm}^{3} \mathrm{~min}^{-1}\right)$ up to $1273 \mathrm{~K}$.

CWAO experiments were performed in a $160 \mathrm{~mL} 316$-stainless steel high pressure batch reactor (Parr Instruments) equipped with a temperature controller (Fig. 1a). The operating conditions were typically as follows: $75 \mathrm{~mL}$ of a TNP model solution, $448 \mathrm{~K}, 500 \mathrm{rpm}$ (confirmed as adequate to ensure the absence of mass transfer limitations), $4.7 \mathrm{MPa}$ of total pressure (0.5 MPa of pure nitrogen, $0.9 \mathrm{MPa}$ of water vapor pressure and 3.3 MPa of air, corresponding to $0.7 \mathrm{MPa}$ of oxygen partial pressure), natural $\mathrm{pH}$ and a catalyst loading of $1.33 \mathrm{~g} \mathrm{~L}^{-1}$. In a typical run, the model solution was placed into the autoclave, flushed with $\mathrm{N}_{2}$ in order to remove dissolved oxygen, pressurised with $0.5 \mathrm{MPa}$ of nitrogen and pre-heated up to the desired temperature. The introduction of air (3.3 MPa) after this pre-heating period was taken as $t=0 \mathrm{~min}$ for the reaction. A non-catalytic blank experiment was also performed with air in the absence of catalyst (WAO). Samples were periodically withdrawn and analysed by high performance liquid chromatography (HPLC).

\subsection{Solar photocatalytic experiments}

A commercial $\mathrm{TiO}_{2}$ powder (AEROXIDE ${ }^{\circledR} \mathrm{TiO}_{2}$ P25) supplied by Degussa (now Evonik) was used as catalyst in photocatalytic experiments, referred hereafter as $\mathrm{P} 25 \mathrm{TiO}_{2}$. The photocatalytic experiments were performed in a solar simulator (Cofomegra SolarBox 1500e, Fig. 1b). Four different initial TNP concentrations were tested $\left(32,64,144\right.$ and $\left.270 \mathrm{mg} \mathrm{L}^{-1}\right)$. In a typical run, the $\mathrm{TiO}_{2}$ catalyst $\left(1 \mathrm{~g} \mathrm{~L}^{-1}\right)$ was added to $75 \mathrm{~mL}$ of the TNP solution. The suspension was first stirred in the dark for $30 \mathrm{~min}$ and then irradiated for $120 \mathrm{~min}$. Air was continuously sparged in the suspension under continuous stirring and the temperature maintained at $303 \pm 3 \mathrm{~K}$. One trial experiment at $500 \mathrm{~W} \mathrm{~m}^{-2}$ irradiance was performed with $270 \mathrm{mg} \mathrm{L}^{-1}$ of TNP and then the power was set at $1000 \mathrm{Wm}^{-2}$ for the rest of the experiments at different TNP concentrations. A blank experiment was also performed for $64 \mathrm{mg} \mathrm{L}^{-1}$ of TNP in the absence of $\mathrm{TiO}_{2}$. Samples withdrawn at regular time intervals were centrifuged for $15 \mathrm{~min}$ and the supernatant liquid was carefully separated for analysis.

\subsection{Analytical techniques}

The concentration of TNP and nitrates in liquid samples were monitored by HPLC with a Hitachi Elite LaChrom HPLC system equipped with a diode array detector (L-2450) and a solvent delivery pump (L-2130) at a flow rate of $1 \mathrm{~mL} \mathrm{~min}^{-1}$. TNP was separated on a Purospher Star RP-18 column $(250 \mathrm{~mm} \times 4.6 \mathrm{~mm}$; $5 \mu \mathrm{m}$ particles) with an isocratic method of an $A: B(40: 60)$ mixture of $3 \%$ acetic acid and $1 \%$ acetonitrile in methanol $(A)$ and $3 \%$ acetic acid in water (B). The concentration of nitrates was analysed with another isocratic method ( $20 \mathrm{mM} \mathrm{NaH}_{2} \mathrm{PO}_{4}$ acidified with $\mathrm{H}_{3} \mathrm{PO}_{4}$ at $\mathrm{pH} 2.8$ ) and using a Hydrosphere $\mathrm{C} 18$ column $(250 \mathrm{~mm} \times 4.6 \mathrm{~mm} ; 5 \mu \mathrm{m}$ particles). Quantification was based on the chromatograms by using the EZChrom Elite chromatography data handling software (Version 3.1.7). The concentrations of TNP and nitrates were determined at the maximum absorbance for each species (359 and $201 \mathrm{~nm}$, respectively). Absorbance and concentrations were found to be linear over the whole range of concentrations under consideration (maximum relative standard deviation of $2 \%$ ).

Total organic carbon (TOC) was determined with a Shimadzu 5000A TOC analyser. This equipment first determines the total carbon (TC) by sample combustion at $973 \mathrm{~K}$ over a Pt catalyst bed, and then the total inorganic carbon (TIC) is measured using phosphoric acid. TOC was calculated by subtracting TIC from TC. The uncertainty in this parameter, quoted as the relative deviation of three separate measurements, was never greater than $2 \%$. Low molecular 

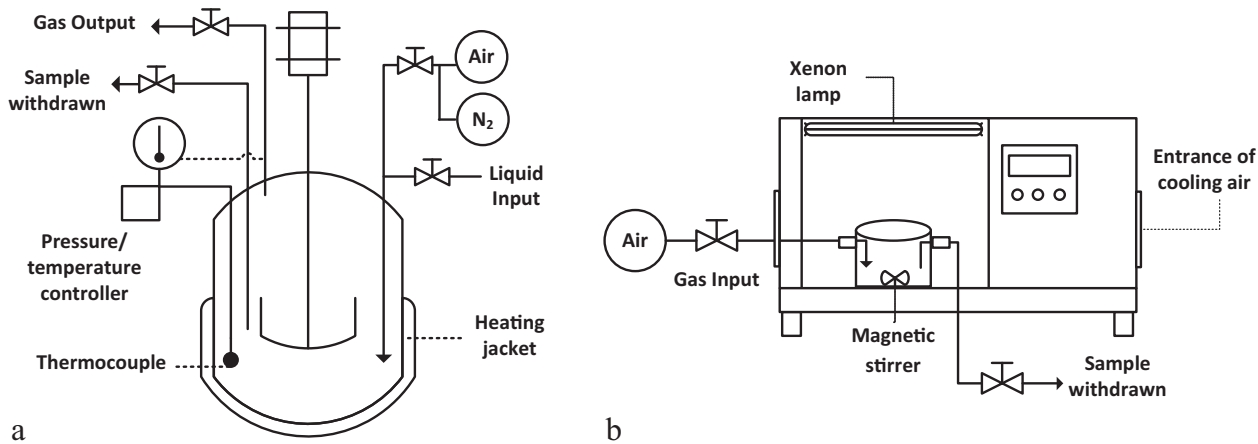

Fig. 1. Experimental set-up for CWAO (a) and photocatalysis (b)

weight carboxylic acids were quantified by ionic chromatography (Dionex DX-600, IonPac AS11-HC column).

The biochemical oxygen demand $\mathrm{BOD}_{5}$ was determined in a WTW equipment (inoLab BSB/BOD 740 with a StirrOX electrode) by measuring the oxygen consumption of a microorganism culture (obtained from garden soil) after 5 days of incubation, in accordance with standard methods [33].

\section{Results and discussion}

To test the performance of the CWAO process, several ACs were used to treat the model solution containing TNP. Some textural and chemical properties of these materials are shown in Table 1 . The textural properties are very similar for the ACs treated according to different methods: $S_{\mathrm{BET}}=845 \pm 25 \mathrm{~m}^{2} \mathrm{~g}^{-1}, S_{\mathrm{MES}}=185 \pm 5 \mathrm{~m}^{2} \mathrm{~g}^{-1}$, and $V_{\mathrm{MIC}}=0.33 \pm 0.01 \mathrm{~cm}^{3} \mathrm{~g}^{-1}$. These textural properties are also similar to those of the original material $\left(S_{\mathrm{BET}}=850 \mathrm{~m}^{2} \mathrm{~g}^{-1}\right.$, $S_{\mathrm{MES}}=190 \mathrm{~m}^{2} \mathrm{~g}^{-1}$, and $V_{\mathrm{MIC}}=0.33 \mathrm{~cm}^{3} \mathrm{~g}^{-1}$ ). However, the $\mathrm{SO}_{2}$ content significantly changes with the conditions applied to prepare each AC $\left(120,420,460,480,520,600\right.$ and $680 \mu \mathrm{mol} \mathrm{g}^{-1}$ for AC, AC5-423, AC5-353, AC10-423, AC18-423, AC10-353 and AC18-353, respectively). Therefore, the carbon materials tested as metal-free CWAO catalysts have similar textural properties but different surface chemistry.

Fig. 2 shows the TNP concentration as a function of time in a blank experiment performed in the absence of catalyst (WAO) and in the CWAO experiments performed with the AC and ACX-Y catalysts. It is observed that the removal of TNP is strongly favoured when the carbon materials are used as catalysts. However, the marked decrease in the TNP concentration during the pre-heating period indicates that TNP was removed, to a substantial degree, by pure adsorption during this period ( $56 \pm 7 \%$ ). The evolution of TNP concentration as a function of time was also determined in experiments performed by introducing 3.3 MPa of nitrogen (instead of air) after the pre-heating period (not shown). For instance, the amount of TNP removed by pure adsorption with the untreated AC was 26\% from 0 to $30 \mathrm{~min}$ (this experiment yielding no nitrates throughout the course of the experiment) while $44 \%$ of TNP was removed in

Table 1

Textural and chemical characterization of ACs.

\begin{tabular}{lllll}
\hline & $S_{\text {BET }}\left(\mathrm{m}^{2} \mathrm{~g}^{-1}\right)$ & $S_{\text {MES }}\left(\mathrm{m}^{2} \mathrm{~g}^{-1}\right)$ & $V_{\text {MIC }}\left(\mathrm{cm}^{3} \mathrm{~g}^{-1}\right)$ & $\mathrm{SO}_{2}\left(\mu \mathrm{mol} \mathrm{g}^{-1}\right)$ \\
\hline AC & 850 & 190 & 0.33 & 120 \\
AC5-353 & 820 & 180 & 0.32 & 460 \\
AC10-353 & 850 & 180 & 0.33 & 600 \\
AC18-353 & 870 & 190 & 0.34 & 680 \\
AC5-423 & 840 & 180 & 0.33 & 420 \\
AC10-423 & 840 & 180 & 0.32 & 480 \\
AC18-423 & 850 & 190 & 0.33 & 520 \\
\hline
\end{tabular}

the same period of time in the CWAO experiment (nitrates being detected). Since both processes (adsorption and reaction) occur simultaneously in CWAO, it is quite difficult to discriminate which fraction is removed by pure adsorption or pure reaction when oxygen is injected in the system, but it is evident that TNP is strongly removed by both processes occurring simultaneously.

Also of interest is to note (Fig. 3) the correlation between the amount of sulphur-containing groups in the carbon materials and TNP adsorption at $t=0 \mathrm{~min}$. The amount of TNP adsorbed during the pre-heating period increases with the sulphur-containing groups as follows: 9.6, 10.7, 11.1, 11.4, 11.6 and $12.9 \mathrm{mg} \mathrm{TNP} \mathrm{g}^{-1} \mathrm{AC}$ for $\mathrm{SO}_{2}$ contents in the AC of $420,460,480,520,600$ and $680 \mu \mathrm{mol} \mathrm{g}^{-1}$, respectively.

Regarding TNP reduction along $30 \mathrm{~min}$ of reaction, it is difficult to distinguish differences in the efficiency of the tested materials because the contribution of adsorption is quite significant in all the experiments. Additionally, the final TOC removal was also quite similar for the treated ACs (70-74\%) but remarkably different from the TOC removal with the original AC (51\%), determined with reference to the initial TNP concentration. Therefore, the effect of the sulphur-containing groups on the catalyst efficiency is not clear, but carbon materials treated with sulphuric acid are in general more efficient than the original AC, not only for TNP removal but also for TOC removal. Although it is quite difficult to distinguish the differences amongst the various ACs treated at $423 \mathrm{~K}$, a decreasing order of efficiency in terms of TNP removal was found for the ACs treated at $353 \mathrm{~K}$; in particular after

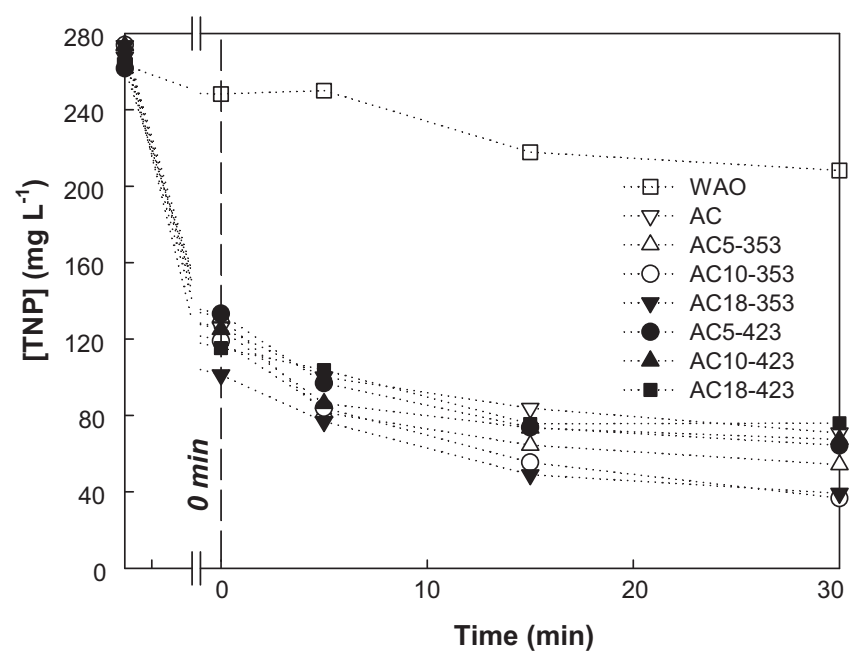

Fig. 2. Evolution of trinitrophenol concentration in non-catalytic and catalytic WAO experiments using the original and treated activated carbons ( $448 \mathrm{~K}, 0.7 \mathrm{MPa}$ oxygen pressure, $1.3 \mathrm{~g} \mathrm{~L}^{-1}$ catalyst loading). 


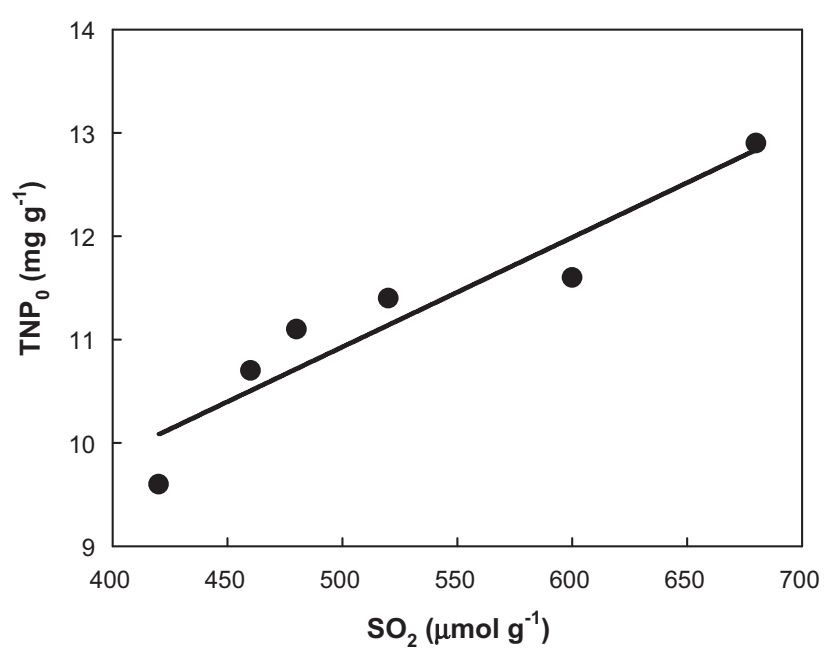

Fig. 3. Amount of TNP adsorbed on different ACs as a function of sulphur concentration in the respective carbon materials.

15 min of reaction: AC18-353 > AC10-353 > AC5-353, which seems to be related with the amount of sulphur-containing groups, i.e., $680 \mu \mathrm{mol} \mathrm{g}^{-1}>600 \mu \mathrm{mol} \mathrm{g}^{-1}>460 \mu \mathrm{mol} \mathrm{g}^{-1}$, respectively.

The amount of nitrates formed during the reaction can give an indication of the extent of oxidation. Once again, the results were quite similar for the materials treated at $423 \mathrm{~K}$ but differences could be observed for those treated at $353 \mathrm{~K}$. For this reason, Table 2 shows results for the set of materials treated at $353 \mathrm{~K}$; for comparative purposes, data from the respective CWAO runs with AC5-423 and the original AC material are also given.

The efficiency of the set of materials treated at $353 \mathrm{~K}$ decreases in the order: AC5-353>AC10-353>AC18-353. This shows that smaller amounts of sulphur-containing groups correspond to larger production of $\mathrm{NO}_{3}{ }^{-}$. Since the introduction of sulphur-containing groups increases the acidity of the materials, the previous observation also suggests that the heterogeneous oxidation of TNP occurs to higher extent on carbon materials with lower acidity (the $\mathrm{pH}$ at the point of zero charge ( $\mathrm{pH}_{\mathrm{PZC}}$ ) is 5.8, 4.1 and 2.4 for AC5-353, AC10353 and AC18-353, respectively). However, the untreated activated carbon, although it exhibits the lowest acidity $\left(\mathrm{pH}_{\mathrm{PZC}}=7.6\right)$, yields the smallest amount of nitrates after $30 \mathrm{~min}$ of reaction, indicating that there are two opposite effects playing a role in this reaction: the introduction of sulphur-containing groups increases the AC efficiency, but the AC efficiency is also favoured by materials with lower acidity. The better performance of carbon materials with lower acidity was already reported when multi-walled carbon nanotubes were used as catalysts for the degradation of oxalic acid [28].

Two consecutive CWAO runs were performed in order to assess the profile of TNP oxidation with the used carbon material. The second run was performed with fresh TNP solution and with the carbon material recovered after the first run. For this set of experiments, the AC5-423 catalyst was randomly selected amongst all the treated samples, since the observed efficiencies were similar.

\section{Table 2}

Concentration of nitrates in CWAO experiments performed with different ACs (448 K, 0.7 MPa oxygen pressure, $1.3 \mathrm{~g} \mathrm{~L}^{-1}$ catalyst loading).

\begin{tabular}{llc}
\hline & {$\left[\mathrm{NO}_{3}^{-}\right]_{15 \mathrm{~min}}\left(\mathrm{mg} \mathrm{L}^{-1}\right)$} & {$\left[\mathrm{NO}_{3}^{-}\right]_{30 \mathrm{~min}}\left(\mathrm{mg} \mathrm{L}^{-1}\right)$} \\
\hline AC & 3.9 & 6.5 \\
AC5-423 & 7.3 & 11.7 \\
AC5-353 & 8.5 & 13.2 \\
AC10-353 & 8.2 & 12.9 \\
AC18-353 & 6.6 & 11.3 \\
\hline
\end{tabular}

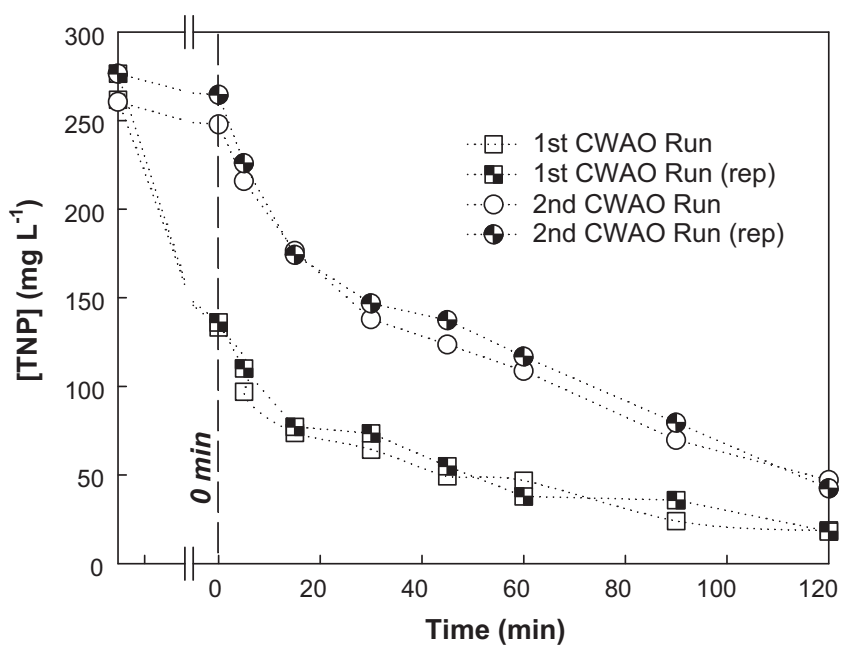

Fig. 4. Evolution of trinitrophenol concentration in CWAO experiments with sample AC5-423 in cyclic (1st and 2nd run) and repeated (rep) runs.

Between each oxidation run, the recovered catalyst was washed with water and dried in the oven at $383 \mathrm{~K}$ for $18 \mathrm{~h}$. These experiments were performed for 120 instead of $30 \mathrm{~min}$. Fig. 4 shows the obtained results, together with the respective duplicates for each experiment (uncertainty of the mean for repeated experiments lower than 5\%). For the fresh catalyst, the TNP concentration after the pre-heating period ( $t=0 \mathrm{~min}$ ) was about $135 \mathrm{mg} \mathrm{L}^{-1}$, which is half of the initial concentration $\left(270 \mathrm{mg} \mathrm{L}^{-1}\right)$, while the TNP concentration at $t=0 \mathrm{~min}$ for the used catalyst was almost the same as the initial TNP concentration loaded into the reactor. Therefore, TNP removal decreases noticeably from the first (fresh catalyst) to the second run (used catalyst), because after the first run the catalyst is saturated with TNP and/or with its reaction intermediates that remain adsorbed on the carbon material after the first run. In the second run, the TNP concentration after 60, 90 and 120 min of CWAO treatment was about 113,75 and $45 \mathrm{mg} \mathrm{L}^{-1}$, respectively, while TOC removal after 120 min was nearly $50 \%$. The original untreated TNP solution was aerobically biorecalcitrant with a $\mathrm{BOD}_{5}$ value equal to zero; nonetheless, CWAO treatment for $120 \mathrm{~min}$ increased $\mathrm{BOD}_{5}$ to $10.2 \mathrm{mg} \mathrm{L}^{-1}$, which corresponds to a $\mathrm{BOD}_{5} / \mathrm{TOC}$ ratio of 0.24 .

In order to study possible changes produced on the carbon material during the CWAO experiments, the treated AC was characterized by $\mathrm{N}_{2}$ adsorption at $77 \mathrm{~K}$ before and after the cyclic CWAO experiments (first and second run). The obtained results are summarized in Fig. 5.

The $\mathrm{N}_{2}$ adsorption isotherm of the fresh sample is characteristic of microporous materials (as confirmed by the large micropore volume and BET surface area collected in Table 3 ) with some mesoporosity. Thus, the activated carbon has a porous structure formed by micro- and mesopores. The isotherms obtained for the samples used in CWAO experiments (first and second run) show that there is a clear influence of the CWAO process on the carbon material, namely a marked decrease of $S_{\mathrm{BET}}$ (from 840 to $391 \mathrm{~m}^{2} \mathrm{~g}^{-1}$ ), $V_{\mathrm{MIC}}$ (from 0.33 to $0.16 \mathrm{~cm}^{3} \mathrm{~g}^{-1}$ ) and $S_{\mathrm{MES}}$ (from 180 to $88 \mathrm{~m}^{2} \mathrm{~g}^{-1}$ ) after the first run. A less pronounced decrease of these parameters was observed in the second run (from 391 to $280 \mathrm{~m}^{2} \mathrm{~g}^{-1}$ for $S_{\mathrm{BET}}$, from 0.16 to $0.12 \mathrm{~cm}^{3} \mathrm{~g}^{-1}$ for $V_{\text {MIC }}$ and from 88 to $58 \mathrm{~m}^{3} \mathrm{~g}^{-1}$ for $S_{\text {MES }}$ ). The evolution of the total volume of pores $\left(V_{\mathrm{T}}\right)$, determined from the $\mathrm{N}_{2}$ uptake at $P / P_{0}=0.95$, as well as the weight loss $(\mathrm{WL})$ obtained by TGA are also presented in Table 3 . These results indicate that adsorption of TNP or intermediate compounds occurs, as already reported for CWAO studies for TNP degradation using activated car- 
Table 3

Textural characterization and weight loss of the AC5-423 material, before and after cyclic CWAO runs (first and second run).

\begin{tabular}{|c|c|c|c|c|c|}
\hline & $S_{\text {BET }}\left(\mathrm{m}^{2} \mathrm{~g}^{-1}\right)$ & $V_{\text {MIC }}\left(\mathrm{cm}^{3} \mathrm{~g}^{-1}\right)$ & $S_{\text {MES }}\left(\mathrm{m}^{2} \mathrm{~g}^{-1}\right)$ & $V_{\mathrm{T}}\left(\mathrm{cm}^{3} \mathrm{~g}^{-1}\right)$ & WL (\%) \\
\hline AC5-423: fresh & 840 & 0.33 & 180 & 0.46 & 8.3 \\
\hline AC5-423: 1st run & 391 & 0.16 & 88 & 0.22 & 11.1 \\
\hline AC5-423: 2nd run & 280 & 0.12 & 58 & 0.16 & - \\
\hline
\end{tabular}

bons produced by chemical activation of olive stones as catalysts [23].

The CWAO mechanism is heterogeneous in nature (as opposed to the homogeneous non-catalytic wet air oxidation), but it can take place in pores of different sizes; thus, the extent of reaction depends on the AC textural properties. The oxidation of TNP takes place into wide micropores $(>0.5 \mathrm{~nm}$ ) when highly microporous ACs are used [23], because all TNP is adsorbed in this type of porosity. The degradation of TNP will also occur on the external surface area (meso- and macropores) when ACs with low microporosity are used, because there is enough TNP available in the liquid phase [23]. Since the ACs tested in the present work have micro- and mesopores, the heterogeneous oxidation mechanism should occur in the wide micropores and larger pores.

In subsequent experiments, the photocatalytic degradation of TNP was investigated. Fig. 6 shows changes in TNP concentration as a function of irradiation time for experiments performed at initial TNP concentrations in the range $32-270 \mathrm{mg} \mathrm{L}^{-1}$. First, it is important to observe that: (i) increased TNP concentrations (270 $\mathrm{mg} \mathrm{L}^{-1}$ ) are very stable regardless of the level of irradiance employed ( 500 or $1000 \mathrm{~W} \mathrm{~m}^{-2}$ ) in photocatalytic experiments, (ii) TNP is not degraded without $\mathrm{TiO}_{2}$ even when the TNP concentration is low (64 $\left.\mathrm{mg} \mathrm{L}^{-1}\right)$ and (iii) light penetration was not reduced at the employed catalyst load of $1 \mathrm{~g} \mathrm{~L}^{-1}$, the photoactivity at $2 \mathrm{~g} \mathrm{~L}^{-1}$ of $\mathrm{TiO}_{2}$ being similar to the one obtained at $1 \mathrm{~g} \mathrm{~L}^{-1}$. In fact, TNP could only be effectively degraded by the photocatalytic treatment at lower concentrations and $1000 \mathrm{~W} \mathrm{~m}^{-2}$ of irradiation. For instance, TNP was reduced by about $78 \%$ after $120 \mathrm{~min}$ at an initial concentration of $144 \mathrm{mg} \mathrm{L}^{-1}$, while total degradation was achieved in 60 and $45 \mathrm{~min}$ when the initial concentration was 64 and $32 \mathrm{mg} \mathrm{L}^{-1}$, respectively. These observations confirm that the photocatalytic process is not appropriate for the degradation of high initial TNP concentrations, but it can effectively be used at lower TNP concentrations; in particular, total degradation was achieved after $60 \mathrm{~min}$

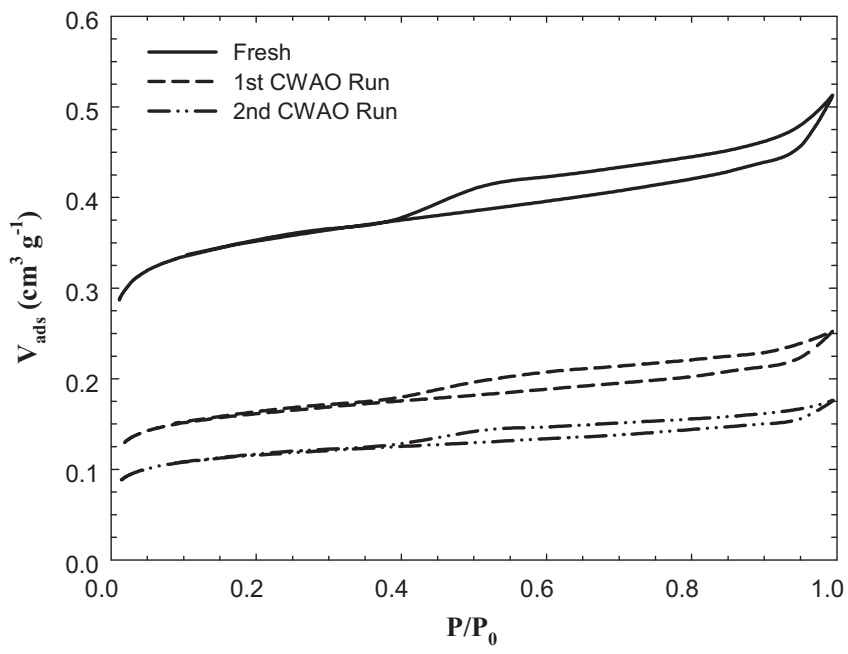

Fig. 5. $\mathrm{N}_{2}$ adsorption isotherms at $77 \mathrm{~K}$ of the $\mathrm{AC} 5-423$ material, before and after cyclic CWAO runs (1st and 2nd run). $V_{\text {ads }}$ is the amount of $\mathrm{N}_{2}$ adsorbed expressed as volume of liquid. for concentrations lower than $64 \mathrm{mg} \mathrm{L}^{-1}$. These results also indicate that photocatalysis can be used as a post-treatment to polish the stream generated from the CWAO of higher TNP concentrations.

To evaluate the eventual process integration, the final effluent from the CWAO treatment with the different modified carbon materials, was treated by photocatalysis. The obtained results are quite similar regardless of the catalyst used, namely complete TNP degradation in $60 \mathrm{~min}$ of photocatalytic treatment and final TOC removals of $79-87 \%$. Since TOC removals by single CWAO were $70-74 \%$, it is possible to enhance the TOC removal by about $10-15 \%$ with photocatalysis.

It is well known that low molecular weight carboxylic acids are the main by-products of AOPs. For this reason, organic acids were quantified after CWAO experiments performed with the modified carbon materials as well as after the integrated treatment comprising photocatalysis. Maleic acid was always detected after the CWAO experiments in concentrations near $39.7 \pm 0.3 \mathrm{mg} \mathrm{L}^{-1}$, decreasing to $33.5 \pm 1.7 \mathrm{mg} \mathrm{L}^{-1}$ after the photocatalytic treatment Malonic acid was not detected after CWAO, but seems to be formed by photocatalysis $\left(6.5 \pm 0.3 \mathrm{mg} \mathrm{L}^{-1}\right)$ probably due to degradation of maleic acid. Other acids, such as formic and acetic acids are formed by CWAO (12.6 $\pm 0.8 \mathrm{mg} \mathrm{L}^{-1}$ and $7.4 \pm 0.4 \mathrm{mg} \mathrm{L}^{-1}$, respectively) but can be effectively degraded by photocatalysis. Only trace amounts of oxalic, citric, pyruvic and valeric acids were detected in some cases $\left(<0.4 \mathrm{mg} \mathrm{L}^{-1}\right)$. The presence of low molecular weight carboxylic acids in the treated solutions can also explain the fact that only a slightly $\mathrm{pH}$ increase (from natural solution $\mathrm{pH}$ of 3.1 up to a maximum of 3.6) was observed after the CWAO and photocatalytic treatments. It is important to refer that even if low molecular weight carboxylic acids are in general biodegradable compounds, it is known that some other species that were not detected can be harmful to the biological treatment even when their concentrations are lower than $1 \mathrm{mg} \mathrm{L}^{-1}$.

In order to obtain a better picture of the integrated treatment, the results of the photocatalytic treatment of the resulting stream after $120 \mathrm{~min}$ of CWAO with the used AC5-423 sample and $270 \mathrm{mg} \mathrm{L}^{-1}$ TNP (Fig. 4) are shown in Fig. 6 (pre-treated). As seen, complete degradation of the residual TNP was achieved after $60 \mathrm{~min}$, together with $82 \%$ TOC reduction, while the $\mathrm{BOD}_{5}$ of the final solution increased to $35 \mathrm{mg} \mathrm{L}^{-1}$ (this corresponds to a $\mathrm{BOD}_{5} / \mathrm{TOC}$ ratio of 2.28 ). Therefore, since (i) photocatalysis is not effective in treating high TNP concentrations, and (ii) the actual industrial waste would be solid at ambient temperatures but liquid at temperatures typically employed in wet oxidation, CWAO (60-120 min) could be used first followed by photocatalysis $(30-120 \mathrm{~min})$ for the complete removal of TNP and effective increase of effluent biodegradability.

\section{Conclusions}

This work proposes an integrated treatment comprising catalytic wet air oxidation and solar-driven heterogeneous photocatalysis for the efficient removal of trinitrophenol from aqueous streams. Relatively mild operating conditions (e.g., up to $120 \mathrm{~min}$ at $448 \mathrm{~K}$ and $0.7 \mathrm{MPa}$ oxygen pressure) in the presence of modified 


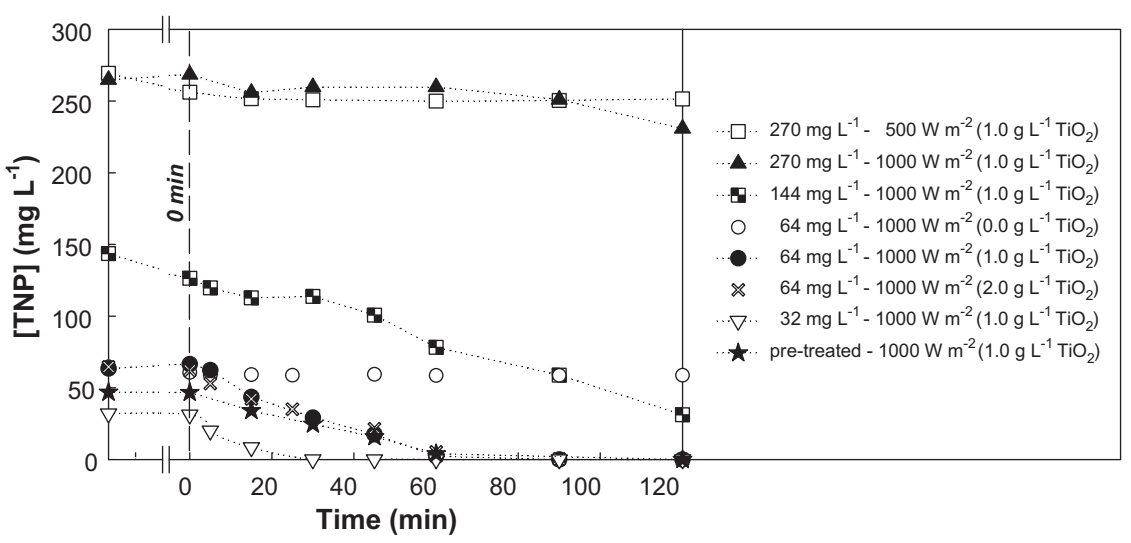

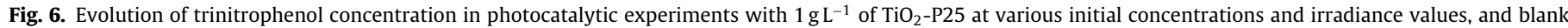
experiments without catalyst and with $2 \mathrm{~g} \mathrm{~L}^{-1}$ of $\mathrm{TiO}_{2}-\mathrm{P} 25$ by using $64 \mathrm{mg} \mathrm{L}^{-1}$ of trinitrophenol.

metal-free carbon materials lead to the removal of a significant amount of the contaminant by CWAO and partially improve the aerobic biodegradability of the stream. In addition, $\mathrm{TiO}_{2}$ based photocatalysis can polish the resulting waters, thus removing completely the residual contaminant and further improving biodegradability.

Since the development of cost-effective and green processes is critical to achieve sustainable water treatment, coupling CWAO with $\mathrm{TiO}_{2}$ photocatalysis may serve this purpose. The use of (i) materials that can act as low cost and stable CWAO catalysts (activated carbons) and photocatalysts $\left(\mathrm{TiO}_{2}\right)$, and (ii) renewable energy, as well as selecting the right treatment sequence and conditions, is evidently a step in the right direction.

\section{Acknowledgements}

LSRE/LCM LA is supported by "Programa de Financiamento Plurianual de Unidades de I\&D/Laboratórios Associados" by Fundação para a Ciência e a Tecnologia (FCT). AMTS acknowledges the financial support from POCI/N010/2006. AK thanks the Research Committee of TUC for subsidising her visit to University of Porto. The financial support from the European Commission (Clean Water - GA n ${ }^{\circ}$ 227017, Seventh Framework Programme (FP7/2007-2013)) is gratefully acknowledged. Clean Water is a Collaborative Project co-funded by the Research DG of the European Commission within the joint RTD activities of the Environment and NMP Thematic Priorities. The work was also partially funded by projects PTDC/AAC-AMB/110088/2009 and NANO/NTecCA/0046/2007, approved by FCT and co-supported by FEDER.

\section{References}

[1] J.M. Herrmann, Heterogeneous photocatalysis: an emerging discipline involving multiphase systems, Catalysis Today 24 (1995) 157-164.

[2] P.R. Gogate, A.B. Pandit, A review of imperative technologies for wastewater treatment. I. Oxidation technologies at ambient conditions, Advances in Environmental Research 8 (2004) 501-551.

[3] A.M.T. Silva, E. Nouli, N.P. Xekoukoulotakis, D. Mantzavinos, Effect of key operating parameters on phenols degradation during $\mathrm{H}_{2} \mathrm{O}_{2}$-assisted $\mathrm{TiO}_{2}$ photocatalytic treatment of simulated and actual olive mill wastewaters, Applied Catalysis B: Environmental 73 (2007) 11-22.

[4] M. Pera-Titus, V. García-Molina, M.A. Baños, J. Giménez, S. Esplugas, Degradation of chlorophenols by means of advanced oxidation processes: a general review, Applied Catalysis B: Environmental 47 (2004) 219-256.

[5] Y.I. Matatov-Meytal, M. Sheintuch, Catalytic abatement of water pollutants, Industrial \& Engineering Chemistry Research 37 (1998) 309-326.

[6] V.S. Mishra, V.V. Mahajani, J.B. Joshi, Wet air oxidation, Industrial \& Engineering Chemistry Research 34 (1995) 2-48.

[7] S. Imamura, Catalytic and noncatalytic wet oxidation, Industrial \& Engineering Chemistry Research 38 (1999) 1743-1753.

[8] S.T. Kolaczkowski, P. Plucinski, F.J. Beltran, F.J. Rivas, D.B. McLurgh, Wet air oxidation: a review of process technologies and aspects in reactor design, Chemical Engineering Journal 73 (1999) 143-160.
[9] F. Larachi, Catalytic wet oxidation: micro-meso-macro methodology from catalyst synthesis to reactor design, Topics in Catalysis 33 (2005) 109134.

[10] J. Levec, A. Pintar, Catalytic wet-air oxidation processes: a review, Catalysis Today 124 (2007) 172-184

[11] A.M.T. Silva, Environmental catalysis from nano- to macro-scale, Materiali in Tehnologije 43 (2009) 113-121.

[12] M. Klavarioti, D. Mantzavinos, D. Kassinos, Removal of residual pharmaceuticals from aqueous systems by advanced oxidation processes, Environment International 35 (2009) 402-417.

[13] A. Cybulski, Catalytic wet air oxidation: are monolithic catalysts and reactors feasible? Industrial \& Engineering Chemistry Research 46 (2007) 40074033.

[14] C.D. Taboada, J. Batista, A. Pintar, J. Levec, Preparation characterization and catalytic properties of carbon nanofiber-supported Pt, Pd, Ru monometallic particles in aqueous-phase reactions, Applied Catalysis B: Environmental 89 (2009) 375-382.

[15] F. Stüber, J. Font, A. Fortuny, C. Bengoa, A. Eftaxias, A. Fabregat, Carbon materials and catalytic wet air oxidation of organic pollutants in wastewater, Topics in Catalysis 33 (2005) 3-50.

[16] C. Aguilar, R. García, G. Soto-Garrido, R. Arriagada, Catalytic wet air oxidation of aqueous ammonia with activated carbon, Applied Catalysis B: Environmental 46 (2003) 229-237.

[17] A. Eftaxias, J. Font, A. Fortuny, A. Fabregat, F. Stüber, Catalytic wet air oxidation of phenol over active carbon catalyst: global kinetic modelling using simulated annealing, Applied Catalysis B: Environmental 67 (2006) 12-23.

[18] M. Santiago, F. Stüber, A. Fortuny, A. Fabregat, J. Font, Modified activated carbons for catalytic wet air oxidation of phenol, Carbon 43 (2005) 2134-2145.

[19] M.E. Suarez-Ojeda, F. Stüber, A. Fortuny, A. Fabregat, J. Carrera, J. Font, Catalytic wet air oxidation of substituted phenols using activated carbon as catalyst, Applied Catalysis B: Environmental 58 (2005) 105-114.

[20] H.T. Gomes, B.F. Machado, A. Ribeiro, I. Moreira, M. Rosário, A.M.T. Silva, J.L. Figueiredo, J.L. Faria, Catalytic properties of carbon materials for wet oxidation of aniline, Journal of Hazardous Materials 159 (2008) 420-426.

[21] T. Cordero, J. Rodríguez-Mirasol, J. Bedia, S. Gomis, P. Yustos, F. García-Ochoa, A. Santos, Activated carbon as catalyst in wet oxidation of phenol: effect of the oxidation reaction on the catalyst properties and stability, Applied Catalysis B: Environmental 81 (2008) 122-131.

[22] A. Quintanilla, J.A. Casas, J.J. Rodriguez, Hydrogen peroxide-promoted-CWAO of phenol with activated carbon, Applied Catalysis B: Environmental 93 (2010) 339-345.

[23] S. Morales-Torres, A.M.T. Silva, A.F. Pérez-Cadenas, J.L. Faria, F.J. MaldonadoHódar, J.L. Figueiredo, F. Carrasco-Marín, Wet air oxidation of trinitrophenol with activated carbon catalysts: effect of textural properties on the mechanism of degradation, Applied Catalysis B: Environmental 100 (2010) 310-317.

[24] M.E. Suárez-Ojeda, A. Fabregat, F. Stüber, A. Fortuny, J. Carrera, J. Font, Catalytic wet air oxidation of substituted phenols: temperature and pressure effect on the pollutant removal, the catalyst preservation and the biodegradability enhancement, Chemical Engineering Journal 132 (2007) 105-115.

[25] Â.C. Apolinário, A.M.T. Silva, B.F. Machado, H.T. Gomes, P.P. Araújo, J.L. Figueiredo, J.L. Faria, Wet air oxidation of nitro-aromatic compounds: reactivity on single- and multi-component systems and surface chemistry studies with a carbon xerogel, Applied Catalysis B: Environmental 84 (2008) 75-86.

[26] S. Yang, W. Zhu, X. Li, J. Wang, Y. Zhou, Multi-walled carbon nanotubes (MWNTs) as an efficient catalyst for catalytic wet air oxidation of phenol, Catalysis Communications 8 (2007) 2059-2063.

[27] S. Yang, X. Li, W. Zhu, J. Wang, C. Descorme, Catalytic activity, stability and structure of multi-walled carbon nanotubes in the wet air oxidation of phenol, Carbon 46 (2008) 445-452.

[28] R.P Rocha, J.P. Sousa, A. M.T. Silva, M. F.R. Pereira, J.L. Figueiredo, Catalytic activity and stability of multiwalled carbon nanotubes in catalytic wet air oxidation of oxalic acid: the role of the basic nature induced by the surface chemistry, Applied Catalysis B: Environmental 104 (2011) 330-336. 
[29] J.P.S. Sousa, A.M.T. Silva, M.F.R. Pereira, J.L. Figueiredo, Wet air oxidation of aniline using carbon foams and fibres enriched with nitrogen, Separation Science \& Technology 45 (2010) 1546-1554.

[30] J.L. Figueiredo, M.F.R. Pereira, M.M.A. Freitas, J.J.M. Órfão, Modification of the surface chemistry of activated carbons, Carbon 37 (1999) 1379-1389.

[31] J.E. Duffy, M.A. Anderson, C.G. Hill, W.A. Zeltner, Photocatalytic oxidation as a secondary treatment method following wet air oxidation, Industrial \& Engineering Chemistry Research 39 (2000) 3698-3706.
[32] H.T. Gomes, S.M. Miranda, M.J. Sampaio, A.M.T. Silva, J.L. Faria, Activated carbons treated with sulphuric acid: catalysts for catalytic wet peroxide oxidation, Catalysis Today 151 (2010) 153-158.

[33] A.D. Eaton, A.E. Greenberg, Standard Methods for the Examination of Water and Wastewater, 16th ed., American Public Health Association, Washington, 1985. 